\title{
Utilization of Anticoagulation and Antiplatelet Therapies in Patients with Atrial Fibrillation and Acute Coronary Syndrome Undergoing Percutaneous Coronary Intervention
}

By Arastoo Mokhtari MD, C. Patel, J.S. Paikin MD, M.K. Natarajan MD

\begin{abstract}
About the Authors
Arastoo Mokhtari is with the Division of Cardiology, McMaster University, Hamilton, Ontario, Canada. C. Patel is with the Hamilton General Hospital, McMaster University, Hamilton, Ontario, Canada. J.S. Paikin is with the Hamilton General Hospital and the Department of Medicine at McMaster University, Hamilton, Ontario, Canada. M.K. Natarajan is with the Hamilton General Hospital, McMaster University, Hamilton, Ontario, Canada, the Population Health Research Institute, McMaster University, and the Department of Medicine, McMaster University, Hamilton, Ontario, Canada. Correspondence: arastoo.mokhtari@medportal.ca
\end{abstract}

\begin{abstract}
Background: The optimal antithrombotic regimen for patients with coexistent atrial fibrillation $(\mathrm{AF})$ and coronary artery disease $(\mathrm{CAD})$ requiring percutaneous coronary intervention (PCI) remains controversial.

Methods: We performed a chart review of 2,645 consecutive patients with non-ST elevation or ST elevation myocardial infarction at a regional cardiac centre, to examine the clinical characteristics and discharge antithrombotic medications of patients with coexistent AF (known or new onset $\mathrm{AF}$ with $\mathrm{CHADS}_{2} \geq 1$ ), treated with PCI.

Results: Among 2,645 patients, 94 eligible patients were analyzed and 30 (32\%) were prescribed triple therapy (TT) at hospital discharge. $\mathrm{CHADS}_{2}$ score was the major predictor of the decision to prescribe TT $(P=0.002)$.

Conclusion: Approximately one-third of the patients with AF undergoing PCI were prescribed TT at hospital discharge. Clinicians are generally following national guidelines and internationallydeveloped consensus statements, and focus on stroke risk despite the risks of bleeding and insufficient evidence supporting the benefits of TT.

\section{Résumé}

Contexte: Le régime optimal antithrombotique pour les patients atteints à la fois de fibrillation atriale (FA) et d'une coronaropathie nécessitant une angioplastie coronarienne percutanée (ACP) demeure controversé.

Méthodologie: Dans un centre régional de cardiologie, nous avons examiné les dossiers médicaux de 2645 patients ayant subi un infarctus du myocarde avec ou sans susdécalage du segment ST. Le but consistait à analyser les caractéristiques cliniques des patients présentant une FA concomitante (ancienne ou nouvelle, avec un indice $\mathrm{CHADS}_{2} \geq 1$ ) traitée par ACP, et les médicaments antithrombotiques prescrits au moment de leur sortie de l'hôpital.
\end{abstract}


Résultats : Parmi les 2645 dossiers, 94 patients admissibles ont été analysés. Trente (32\%) sétaient vus prescrire une trithérapie (TT) à leur sortie de l'hôpital. L'indice $\mathrm{CHADS}_{2}$ était le principal indicateur prévisionnel pris en compte dans la décision de prescrire la TT $(P=0,002)$. Conclusion : Environ un tiers des patients atteints de FA et ayant subi une ACP se sont vus prescrire une TT à leur sortie de l'hôpital. En général, les cliniciens suivent les directives nationales et les protocoles consensuels élaborés à l'international et se concentrent sur le risque d'ictus, malgré les risques de saignements et le manque de données probantes soutenant les avantages d'une TT.

\section{BACKGROUND}

Dual antiplatelet therapy (DAPT) including Aspirin and a $\mathrm{P}_{2} \mathrm{Y}_{12}$ receptor antagonist is recommended for patients who undergo percutaneous coronary intervention (PCI) with stent implantation. ${ }^{1,2}$ DAPT is superior to oral anticoagulants (OAC) in preventing stent thrombosis, ${ }^{3}$ while $\mathrm{OAC}$ is superior to DAPT in reducing stroke in patients with atrial fibrillation (AF). ${ }^{4,5}$ It is estimated that $5-8 \%$ of patients sustaining an acute coronary syndrome (ACS) have concomitant $\mathrm{AF}^{6,7}$ The optimal antithrombotic regimen for patients with coexistent $\mathrm{AF}$ and coronary artery disease (CAD) requiring PCI remains controversial. In patients with $\mathrm{AF}$ and $\mathrm{CHADS}_{2}$ stroke risk score $\geq 1$, consensus statements suggest that triple therapy (TT), defined as a combination of DAPT + OAC, be utilized in patients undergoing PCI with ACS. ${ }^{8,9}$ However, there is data indicating no improved efficacy of treatment with TT compared with DAPT alone, while exposing patients to increased bleeding risk. ${ }^{7,10,11}$ Major bleeding has been proven to be independently associated with death in patients following an ACS. ${ }^{12}$ Therefore, balancing the thromboembolic and bleeding risk is critical in patients with a recent ACS.

Large randomized trials have indicated that compared with warfarin, novel oral anticoagulants (NOAC's) are at least as effective as, and are associated with reduced rates of major, fatal and intracranial bleeding in patients with non-valvular AF. ${ }^{13}$ Due to the favourable safety profile, NOACs are being evaluated against warfarin in patients with AF undergoing PCI. Three of these trials are ongoing (RE-DUAL PCI, AUGUSTUS, ENTRUST-AF-PCI) ${ }^{14-16}$ and the fourth is the recently published PIONEER AF-PCI trial, which showed that reduced-dose rivaroxaban combined with clopidogrel lowered the risk of bleeding compared with TT with warfarin. ${ }^{17}$

Despite the emergence of these recent data, the highest risk patients remain excluded from large randomized trials, and thus sound clinical judgment will remain the cornerstone in caring for these patients. In the current study, we aim to describe the local practice patterns of clinicians making treatment decisions for patients with new or existing AF, who present with an ACS and undergo PCI.

\section{METHODS}

A retrospective and prospective chart review was performed on 2,645 consecutive patients presenting with ST elevation myocardial infarction (STEMI) and non-ST elevation myocardial elevation (NSTEMI) to 3 academic hospitals affiliated with McMaster University and 8 community hospitals located in Local Health Integrated Network (LHIN) 4, Ontario, Canada from January to December 2014. Of those, 1,458 patients had undergone PCI with stent implantation; and, 124 patients were identified to have concomitant AF (Figure 1). Inclusion criteria for our study were: admission to hospital for either STEMI or NSTEMI, known or new onset AF with $\mathrm{CHADS}_{2} \geq 1$, coronary angiography demonstrating at least one epicardial coronary artery with $a \geq 70 \%$ stenosis, and successful PCI with stent implantation. Patients who expired before discharge were excluded from the analysis. Clinical and demographic characteristics of patients were summarized. DAPT and TT groups were identified by reviewing medication records from discharge summaries or copies of discharge prescriptions. DAPT was defined as Aspirin plus clopidogrel (75 mg once daily) or ticagrelor ( $90 \mathrm{mg}$ twice daily), while TT was defined as DAPT plus an OAC; including either warfarin or novel oral anticoagulants (NOAC). We analyzed the $\mathrm{CHADS}_{2}$ and ATRIA (Anticoagulation and Risk factors in Atrial fibrillation) scores according to treatment groups. ${ }^{18,19}$ Statistical analysis was performed using SAS/STAT version 9.3 (SAS Institute Inc., Cary, NC). Categorical data was compared using Chi-square testing. Continuous data comparison was performed applying the Wilcoxon test and Cochran-Armitage test for trends. A binary logistic regression model was developed to identify the clinical predictors of discharge groups based on their $\mathrm{CHADS}_{2}$ and ATRIA scores (Figure 2 and Figure 3). The cut-off for statistical significance was a $P$-value of $<0.05$.

\section{RESULTS}

Demographic and clinical characteristics of patients are described in Table 1. Ninety four out of 124 patients with ACS and a prior or new diagnosis of AF were included in the final analysis. The mean (s.d.) age was 74 years (10 years) and $55.3 \%$ were male. In our cohort, $59.6 \%$ of patients sustained a STEMI and 54.3\% 


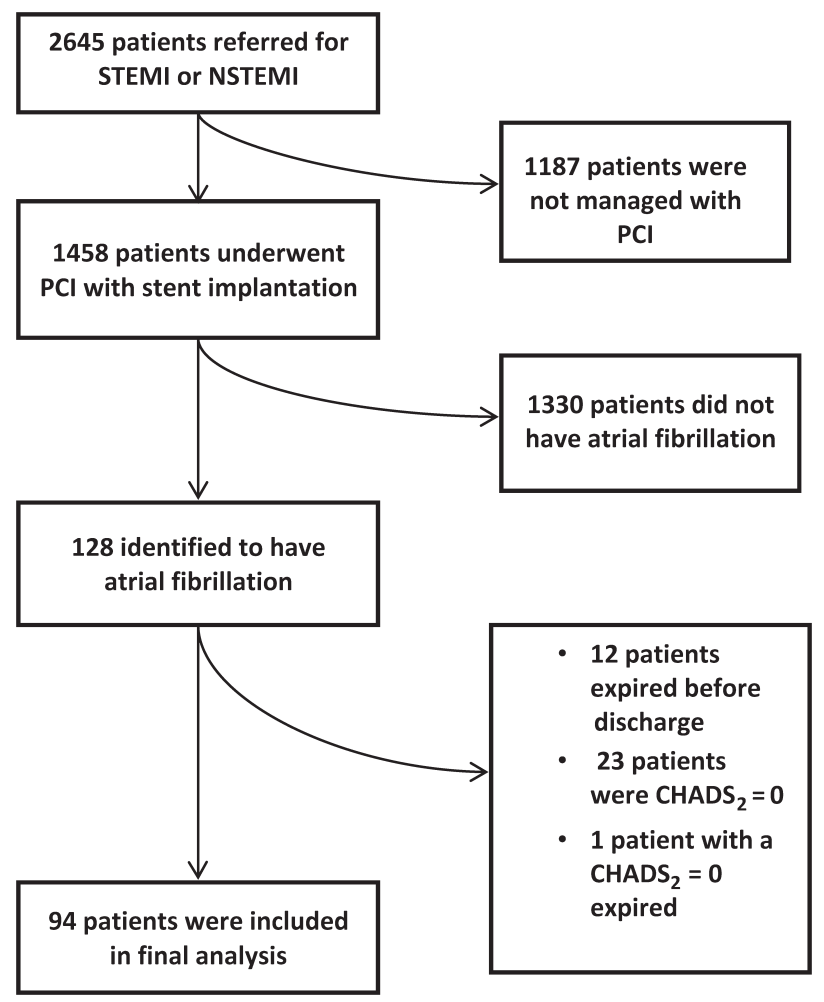

Figure 1. Flow chart of study cohort.

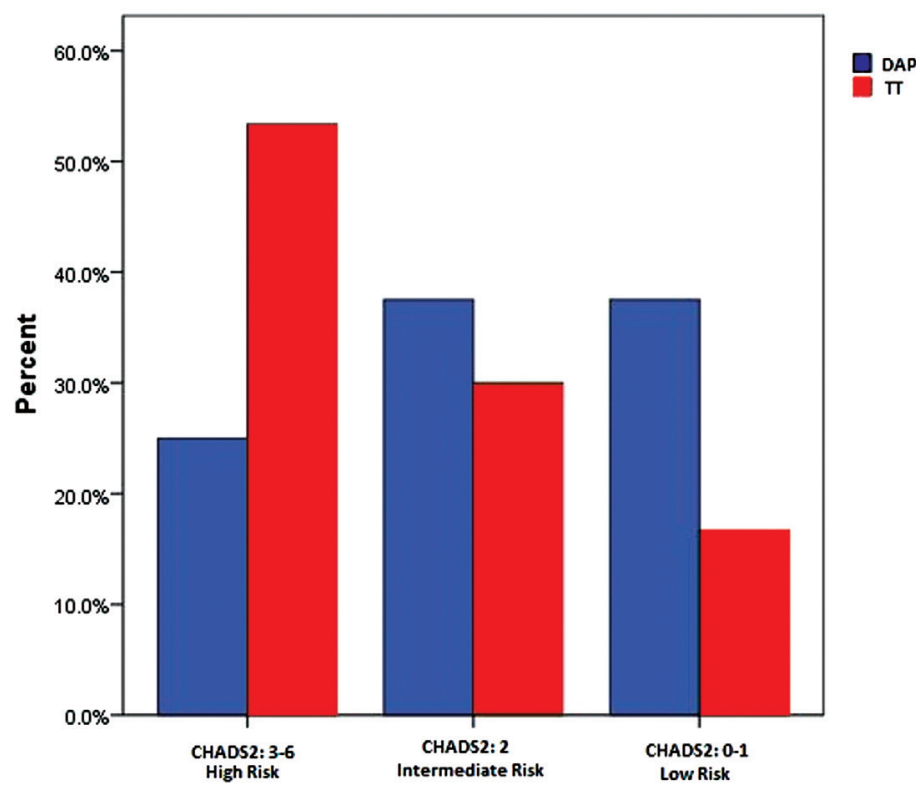

Figure 2. Use of triple therapy versus dual antiplatelet therapy at the time of discharge in different stroke risk groups predicted by their $\mathrm{CHADS}_{2}$ score.

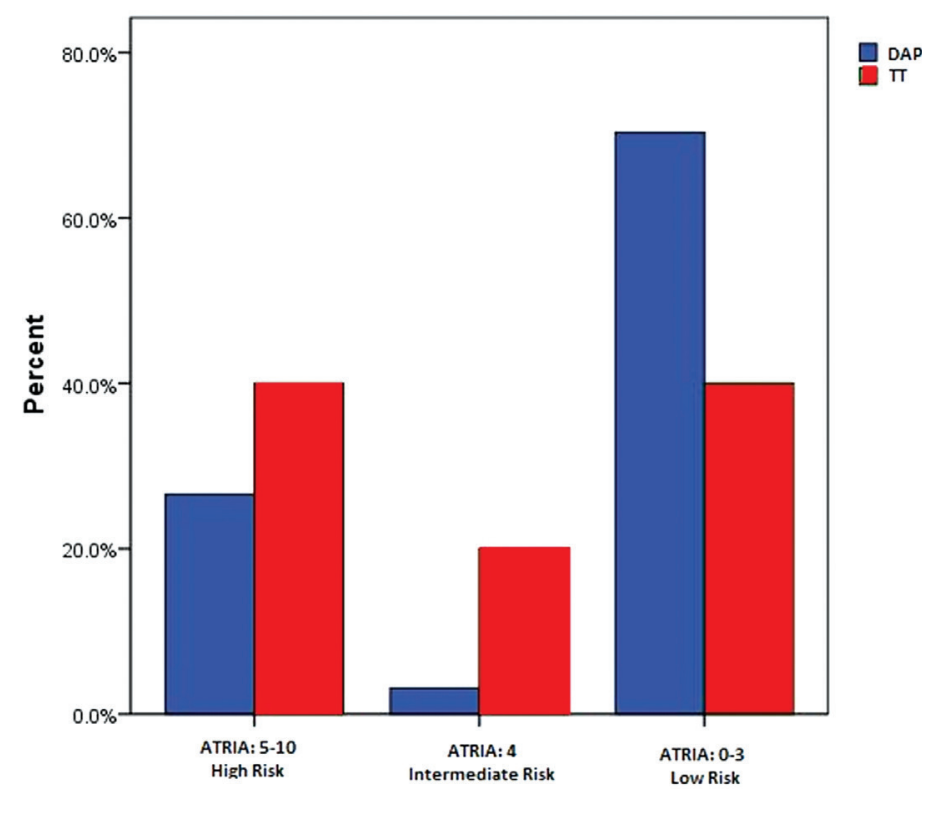

Figure 3. Use of triple therapy versus dual antiplatelet therapy at the time of discharge in different bleeding risk groups predicted by their ATRIA score.

had single vessel CAD. Overall, $32 \%(n=30)$ of patients were discharged on TT of whom $55.6 \%$ were prescribed a combination of DAPT and a NOAC while the remaining patients were prescribed conventional TT (DAPT+warfarin) (Table 2). The median $\mathrm{CHADS}_{2}$ score in the DAPT and TT groups were 2 and 3 , respectively $(P=0.001)$. The median ATRIA bleeding risk in DAPT and TT groups were 3 and 4 , respectively $(P=0.008)$. The $P$-value for trend of $\mathrm{CHADS}_{2}$ and ATRIA scores were $<0.0001$ and 0.001 , respectively. However, these 2 trends were not significantly different from one another $(P=0.26)$. In a logistic regression analysis with both $\mathrm{CHADS}_{2}$ and ATRIA scores included in the model, the $\mathrm{CHADS}_{2}$ score was significantly different between both groups $(P=0.002)$, while the ATRIA score was not $(P=$ 0.58 ). In patients who were prescribed $\mathrm{TT}, 36.6 \%$ had a history of stroke or TIA compared with $10.9 \%$ in the DAPT group $(P$ $=0.005$ ). Additionally, the patients who were discharged on TT were more likely to have been treated with an OAC prior to admission, compared with those in the DAPT group (70\% vs $17.1 \% ; P<0.001)$. We observed that there was proportionally more use of a BMS in patients with AF (41.5\% of the 94 patients) compared with BMS being used in the whole cohort $(15 \%$ of the 1,458 patients).

There was no statistically significant difference in the likelihood of being discharged on TT based on whether patients were hospitalized at a community or academic hospital (44\% 
vs. $56 \%, P=0.42$ ). Academic hospitals had the availability of a thrombosis service and they provided a consultation on $18 \%$ of the patients analyzed at those hospitals. The thrombosis service was generally involved in the care of patients with higher $\mathrm{CHADS}_{2}$ scores, and the involvement of the thrombosis service was associated with a significantly increased use of TT $(P=0.002)$.

\section{DISCUSSION}

Our results indicate that approximately one-third of patients were prescribed TT at hospital discharge, while the remaining patients received DAPT alone. No patients received a combination of single antiplatelet therapy and an OAC. Although both the $\mathrm{CHADS}_{2}$ and ATRIA scores were significantly higher in the TT group, the $\mathrm{CHADS}_{2}$ score more strongly predicted the use of TT in our local practice. Our results also showed that OAC use prior to admission increased the probability of TT use upon discharge. Furthermore, the current study reveals that in patients discharged on TT, a combination of Aspirin, a $\mathrm{P}_{2} \mathrm{Y}_{12}$ inhibitor and NOAC were prescribed more often than conventional TT with warfarin despite the lack of clear evidence about their safety profile. ${ }^{20,21}$

An analysis of the AVIATOR registry, which included patients with a similar mean $\mathrm{CHADS}_{2}$ score as in our study (2.7 in the AVIATOR registry vs. 2.3 in our cohort) reported that $41.2 \%$ of patients were prescribed TT at discharge ${ }^{22}$ compared with $31.9 \%$ in our cohort. This indicates that some practice variability exists among clinicians when considering treatment with TT in patients with similar risk profiles. The AVIATOR registry data also demonstrated that patients who were discharged on TT had a higher risk of stroke defined by their $\mathrm{CHADS}_{2}$ score but in contrast to our results, their bleeding risk score was not higher than the DAPT group. Our results were, however, consistent with another retrospective study within a large registry, which reported greater use of $\mathrm{OAC}$ at discharge among patients with both higher stroke and bleeding risk. ${ }^{23}$ This observation highlights

Table 1. Demographic and Clinical Characteristics of Patients

\begin{tabular}{|c|c|c|c|c|}
\hline & $\begin{array}{l}\text { Total } \\
N=94\end{array}$ & $\begin{array}{l}\text { DAPT } \\
N=64\end{array}$ & $\begin{array}{c}T \\
N=30\end{array}$ & $P$ \\
\hline Age median (years) & 75.5 & 75 & 76.5 & 0.29 \\
\hline Male (\%) & 55.3 & 57.8 & 50 & 0.76 \\
\hline Hypertension (\%) & 87.2 & 87.5 & 86.6 & 0.57 \\
\hline Diabetes Mellitus (\%) & 28.7 & 25 & 36.6 & 0.17 \\
\hline History of Stroke / TIA (\%) & 19.1 & 10.9 & 36.6 & 0.005 \\
\hline Left ventricular ejection fraction (\%) & 42.7 & 43.1 & 41.8 & 0.49 \\
\hline Hemoglobin (g/dL) & 134.4 & 137.8 & 127.2 & 0.016 \\
\hline Glomerular filtration rate $(\mathrm{mL} / \mathrm{min})$ & 65.9 & 67.3 & 62.8 & 0.55 \\
\hline $\mathrm{CHADS}_{2}$ Score (median) & 2 & 2 & 3 & 0.001 \\
\hline ATRIA Score (median) & 3 & 3 & 4 & 0.008 \\
\hline Oral anti-coagulation (\%) (Before admission) & 34 & 17.1 & 70 & $<0.001$ \\
\hline Inpatient thrombosis service consult (\%) & 18 & 9.3 & 36.6 & 0.002 \\
\hline Bare metal stent (\%) & 41.5 & 35.9 & 53.3 & 0.08 \\
\hline ST-elevation myocardial infarction (\%) & 59.6 & 59.3 & 60 & 0.56 \\
\hline
\end{tabular}

DAPT = dual antiplatelet therapy; TT = triple therapy; TIA = transient ischemic attack; ATRIA = anticoagulation and risk factors in atrial fibrillation.

Table 2. Distribution of Antithrombotic Regimens at the Time of Discharge

\begin{tabular}{lcc|}
$\begin{array}{c}\text { Treatment } \\
\text { Regimen }\end{array}$ & Patients $(n)$ & $\begin{array}{c}\text { \% of patients } \\
\text { on given } \\
\text { regimen }\end{array}$ \\
\hline DAPT & 64 & 68 \\
\hline TT(DAPT+Warfarin) & 13 & 14 \\
\hline TT(DAPT+NOAC) & 17 & 18 \\
\hline Total & 94 & 100 \\
\hline
\end{tabular}

DAPT $=$ dual antiplatelet therapy; NOAC $=$ novel oral anticoagulant; $\mathrm{TT}=$ triple therapy. the important point that many major predictors of stroke, such as advanced age, are also important risk factors for bleeding.

TT in our local clinical practice was used more selectively and was predominantly for those patients with a high $\mathrm{CHADS}_{2}$ score $(\geq 3)$. Our data also show that clinicians favoured use of TT even in patients with higher bleeding risk despite the lack of robust evidence. ${ }^{24}$

Our study was designed to describe practice patterns only, and therefore, one limitation was the inability to report patient outcomes following hospital discharge. Secondly, given the observational and retrospective nature of our study and 
the relatively small study cohort we are only able to describe associations. Thirdly, there are unmeasured variables such as frailty, patients' overall goals of care, and personal preferences that could contribute to the ultimate decision for a given antithrombotic regimen, which were not captured in our study. Fourthly, the type and dose of NOAC were not collected in our study. Our study was unique in assessing practice parameters such as discharge settings (academic versus community hospitals) and describing the effect of the involvement of a thrombosis service in making treatment decisions.

The choice of the most favourable antithrombotic regimen in patients with AF and ACS undergoing PCI remains an area of clinical debate. There were no patients in our study cohort discharged on a combination of a $\mathrm{P}_{2} \mathrm{Y}_{12}$ inhibitor and warfarin alone, a regimen evaluated in the previously published WOEST trial. ${ }^{25}$ This observation indicates either a knowledge gap or reluctance among clinicians in applying the results of the WOEST study. The results of the PIONEER AF-PCI trial suggest that a WOEST study type strategy of reduced-dose rivaroxaban with single antiplatelet therapy (clopidogrel) is an attractive alternative to warfarin because of the substantial reduction in major bleeding. This trial has been criticized because it was not powered for ischemic events, had an open-label design, and tested doses of rivaroxaban that had not been previously evaluated ${ }^{26}$ However, PIONEER AF-PCI and ongoing trials in this area will hopefully strengthen the body of evidence and lead to more informed clinical decision making and improved patient care. Despite the growing evidence in this area, the uptake will remain slow among clinicians until emergence of further robust evidence and variability of practice will persist as partially reflected in the current study.

\section{Disclosure}

There was no dedicated funding for this study.

None of the authors have any disclosures relevant to this study.

\section{REFERENCES}

1. Tanguay JF, Bell AD, Ackman ML, et al. Focused 2012 Update of the Canadian Cardiovascular Society Guidelines for the Use of Antiplatelet Therapy. Can J Card 2013; 29(11):1334-34.

2. Windecker S, Kolh P, Alfonso F, et al. European Society of Cardiology Working Group on Thrombosis. 2014 ESC/EACTS Guidelines on myocardial revascularization. Eur Heart J 2014;35(37):2541-619.

3. Schomig A, Neumann FJ, Kastrati A, et al. A randomized comparison of antiplatelet and anticoagulant therapy after the placement of coronary artery stents. N Engl J Med 1996;334:1084-9.

4. Connolly S, Pogue J, Hart R, et al. Clopidogrel plus aspirin versus oral anticoagulation for atrial fibrillation in the Atrial Fibrillation Clopidogrel Trial with Irbesartan for Prevention of Vascular Events (ACTIVE W): a randomised controlled trial. Lancet 2006;367:1903-12.

5. Verma A, Cairns JA, Mitchell LB, et al. 2014 Focused Update of the Canadian Cardiovascular Society Guidelines for the Management of Atrial Fibrillation. Can J Card 2014;30(10):1114-30.
6. McManus DD, Huang W, Domakonda KV, et al. Trends in atrial fibrillation in patients hospitalized with an acute coronary syndrome. Am J Med 2012;125(11):1076-84.

7. Chen CF, Chen B, Zhu J, et al. Antithrombotic therapy after percutaneous coronary intervention in patients requiring oral anticoagulant treatment. Herz 2015;40(8):1070-83.

8. Faxon DP, Eikelboom JW, Berger PB, et al. Consensus document: antithrombotic therapy in patients with atrial fibrillation undergoing coronary stenting: A North-American perspective. Thromb Haemost 2011;106:572-84.

9. Lip GY, Windecker S, Huber K, et al. Management of antithrombotic therapy in atrial fibrillation patients presenting with acute coronary syndrome and/or undergoing percutaneous coronary or valve interventions: a joint consensus document of the European Society of Cardiology Working Group on Thrombosis, European Heart Rhythm Association(EHRA), European Association of Percutaneous Cardiovascular Interventions (EAPCI) and European Association of Acute Cardiac Care (ACCA) endorsed by the Heart Rhythm Society (HRS) and Asia-Pacific Heart Rhythm Society (APHRS). Eur Heart J 2014;35:3155-79.

10. Hess CH, Peterson ED, Peng SA, et al. Use and outcomes of triple therapy among older patients with acute myocardial infarction and atrial fibrillation. J Am Coll Cardiol 2015;66:616-27.

11. Lamberts M, Olesen JB, Ruwald MH, et al. Bleeding after initiation of multiple antithrombotic drugs, including triple therapy, in atrial fibrillation patients following myocardial infarction and coronary intervention: a nationwide cohort study. Circulation 2012;126(10):1185-93.

12. Eikelboom JW, Mehta SR, Anand SS, et al. Adverse impact of bleeding on prognosis in patients with acute coronary syndromes. Circulation 2006;114(8):774-82.

13. Ruff CT, Giugliano RP, Braunwald E, et al. Comparison of the efficacy and safety of new oral anticoagulants with warfarin in patients with atrial fibrillation: a meta-analysis of randomised trials.

14. ClinicalTrials.gov. Evaluation of Dual Therapy with Dabigatran vs. Triple Therapy with Warfarin in Patients with AF That Undergo a PCI with Stenting (REDUAL-PCI). Lancet. 2014 Mar 15;383(9921):955-62. doi: 10.1016/S01406736(13)62343-0. Epub 2013 Dec 4. Available at: https://clinicaltrials.gov/ct2/ show/NCT02164864.

15. ClinicalTrials.gov. A Study of apixaban in patients with atrial fibrillation, not caused by a heart valve problem, who are at risk for thrombosis (blood clots) due to having had a recent coronary event, such as a heart attack or a procedure to open the vessels of the heart. Available at: https://clinicaltrials gov/ct2/show/NCT02415400

16. ClinicalTrials.gov. Edoxaban Treatment Versus Vitamin K Antagonist in Patients With Atrial Fibrillation Undergoing Percutaneous Coronary Intervention (ENTRUST-AF-PCI). Available at: https://clinicaltrials.gov/ct2/ show/NCT02866175

17. Gibson CM, Mehran R, Bode C, et al. Prevention of bleeding in patients with atrial fibrillation undergoing PCI. N Engl J Med 2016;375:2423-34

18. Gage BF, Waterman AD, Shannon W, et al. Validation of clinical classification schemes for predicting stroke: results from the National Registry of Atrial Fibrillation. JAMA 2001;285:2864-70.

19. Fang MF, Go AS, Chang Y, et al. A new risk scheme to predict warfarinassociated hemorrhage, the ATRIA (Anticoagulation and Risk Factors in Atrial Fibrillation Study). J Am Coll Cardiol 2011;58(4):395-401.

20. Tsu LV, Dager WE. Safety of new oral anticoagulants with dual antiplatelet therapy in patients with acute coronary syndromes. Ann Pharmacother 2013;47(4):573-7.

21. Oldgren J, Wallentin L, Alexander JH, et al. New oral anticoagulants in addition to single or dual antiplatelet therapy after an acute coronary syndrome:a systematic review and meta-analysis. Eur Heart J 2013;34(22): 1670-80.

22. Mennuni MG, Halperin JL, Bansilal S, et al. Balancing the risk of bleeding and stroke in patients with atrial fibrillation after percutaneous coronary intervention (from the AVIATOR Registry). Am J Cardiol 2015;116:37-42. 
23. Lopes RD, Li L, Granger CB, et al. Atrial fibrillation and acute myocardial infarction: antithrombotic therapy and outcomes. Am J Med 2012; 125:897-905.

24. Skanes A, Healey JS, Cairns JA, et al. Focused 2012 Update of the Canadian Cardiovascular Society Atrial Fibrillation Guidelines: Recommendations for Stroke Prevention and Rate/Rhythm Control. Can J Cardiol. 2012 May;28(3):396.
25. Dewilde WJ, Oirbans T, Verheugt FW, et al. Use of clopidogrel with or without aspirin in patients taking oral anticoagulant therapy and undergoing percutaneous coronary intervention: an open-label, randomized, controlled trial. Lancet 2013;381:1107-15.

26. Jolly SS, Natarajan MK. Atrial fibrillation and PCI - do we still need aspirin? N Engl J Med 2016; 375:2490-92. 